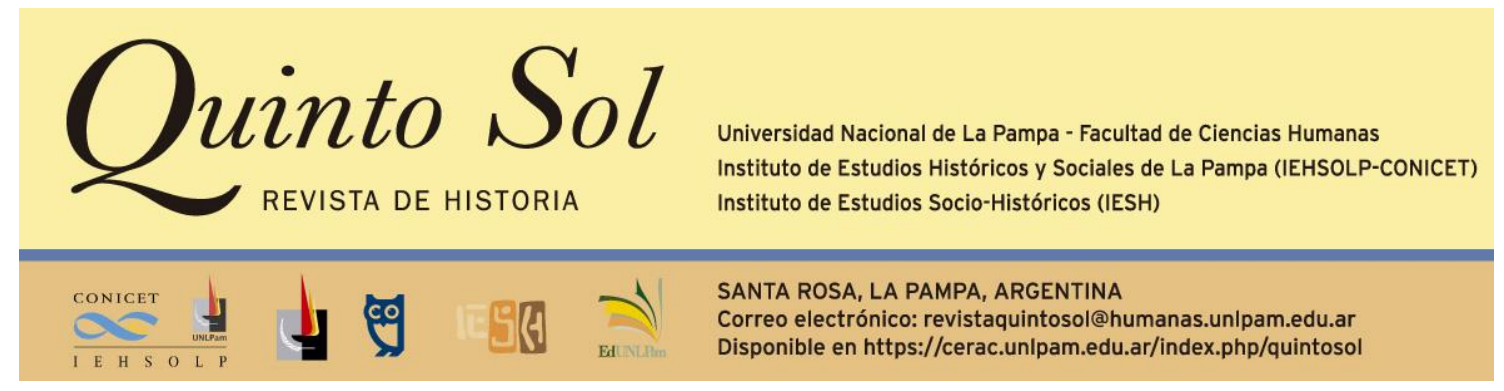

Quinto Sol, vol. 23, n 1, enero-abril 2019, ISSN 1851-2879, pp. 1-4

DOI: http://dx.doi.org/10.19137/qs.v23i1.3474

Esta obra se publica bajo licencia Creative Commons 4.0 Internacional. (Atribución-No ComercialCompartir Igual)

\title{
Magdalena Candioti. Un maldito Derecho. Leyes, jueces y revolución en la Buenos Aires republicana, 1810-1830. Buenos Aires: Ediciones Didot, 2017, 260 páginas.
}

\section{Lucas Rebagliati}

Consejo Nacional de Investigaciones Científicas y Técnicas

Universidad de Buenos Aires

Universidad Nacional de Avellaneda

Argentina

Correo electrónico: lucasrebagliati@hotmail.com

Un maldito Derecho...además de ser una investigación profundamente original, es el primer libro de Magdalena Candioti en calidad de autora. Sin embargo, hace ya un par de años una serie de artículos y una compilación suya -junto con Juan Manuel Palacio- permitían vislumbrar un sólido manejo de los nuevos aportes y metodologías de un área que en las últimas décadas ha conocido una notable expansión en la historiografía latinoamericanista. Nos referimos a un conjunto heterogéneo de estudios de distintos orígenes y tendencias que tienen una preocupación en común. La inquietud acerca de cómo las sociedades del pasado juzgaron aquellas conductas consideradas desviadas y delictivas. El libro representa lo sustancial de la tesis doctoral que Candioti defendió en 2010 en la Universidad de Buenos Aires, gracias el financiamiento del Consejo Nacional de Investigaciones Científicas y Técnicas (CONICET). 
En la "Introducción" ya queda definida la discusión que se propone desplegar la autora. Frente a una historiografía que en las últimas décadas viene resaltando la continuidad entre el viejo orden jurídico colonial y el revolucionario en el mundo hispanoamericano, Candioti busca enfatizar "el carácter revolucionario de la revolución y la centralidad performativa de los discursos". Las transformaciones radicales operadas por el proceso revolucionario desencadenado por la invasión napoleónica a la península, habrían alcanzado también a la justicia porteña según la autora. Otras dos cuestiones resaltan en esta "Introducción". En primer lugar, la habilidad para plantear buenas preguntas sobre el objeto de estudio, tal como lo señala Marcela Ternavasio en el prólogo. Estos interrogantes son vitales para diferenciarse de la historiografía dominante que ya hemos mencionado, como también de los estudios fundadores de la historia del derecho en nuestro país, los cuales planteaban una división tajante entre el derecho indiano y el "derecho patrio argentino". De esta forma, la contribución de Candioti se posiciona como una suerte de tercera vía. En segundo término, se encuentra una prolija y minuciosa reconstrucción de la cultura jurídica-política de antiguo régimen que imperaba en la época colonial.

El libro se estructura en tres partes, cada una de ellas con dos capítulos en su interior. La primera se titula "La revolución jurídico-política. Retórica y diseños institucionales para la nueva república". El capítulo 1 describe como una vez producido el desplazamiento del virrey e instalada la Junta, un sector de la dirigencia política esbozó discursos muy críticos sobre el derecho y los jueces de antiguo régimen durante la primera década revolucionaria. El campo jurídico fue problematizado, mientras sucesivos reglamentos y decretos provocaron cambios institucionales en la esfera de la organización judicial. La retórica del imperio de la ley y la división de poderes, ajena y contrapuesta a la cultura jurisdiccional colonial, fue ganando terreno y legitimidad entre los actores. Pese a ello, la autora se encarga de aclarar que tales cambios no fueron "sistemáticos, globales o progresivos". Tampoco "se instalaron de modo inmediato ni impusieron rupturas abruptas en la institucionalidad y los procedimientos". Pero la nueva retórica no solo cumplió un rol central, sino que había llegado para quedarse, y se consolidaría y profundizaría en la década siguiente.

Precisamente, el capítulo 2 aborda el período conocido como "La feliz experiencia", donde la circulación de los nuevos discursos y principios encontraría una materialización institucional más acabada. La abolición de los cabildos y la implementación de un régimen republicano y representativo a nivel provincial, tuvo su necesario correlato en la esfera judicial. El establecimiento de una justicia de primera instancia letrada y rentada en la ciudad se combinó con jueces de paz en la campaña que conservaban atributos de antiguo régimen, aunque resignificados en un nuevo contexto. Pero las transformaciones no se agotarían allí. La creación de un registro oficial de leyes, la eliminación de los "odiosos fueros", la intensificación del debate en torno a distintas cuestiones relativas a la justicia fueron fenómenos que jalonaron esta década. Sin embargo, el ímpetu reformador tuvo sus límites. El contexto de provisionalidad marcado por el fracaso de los dos proyectos constitucionales sancionados -en 1819 y 1826- obligaba a los actores a posponer una verdadera reforma de la justicia.

La segunda parte del libro, titulada "La revolución erudita. Juristas repensando el derecho y la justicia" se abre con un capítulo 3 centrado en el surgimiento y devenir de la Academia de Jurisprudencia. Allí la autora, a partir del análisis de las trayectorias 
individuales de Manuel Antonio de Castro, Guret de Bellemare y Valentín Alsina delinea tres tipos de juristas en esa época: los más apegados a la tradición, los afectos a la importación de novedades ideológicas y una joven generación interesada en aunar viejos y nuevos principios en pos de crear un nuevo orden. Los juristas formados en esta institución intervinieron activamente en discusiones públicas -a través de la prensa- sobre la reforma judicial rioplatense. La certeza colonial de un mundo jurídico de origen divino e indisponible había dado lugar a la incerteza revolucionaria nacida de la concepción de que el orden jurídico debía ser producto de la agencia humana. Así es como el derecho dejó de ser concebido como una atribución o potestad innata de toda autoridad, para pasar a ser imaginado como un saber especializado en manos de expertos.

En el capítulo 4 se aborda otra institución nacida al calor de la revolución y las reformas rivadavianas: la Universidad de Buenos Aires. Un repaso por los contenidos impartidos por profesores como Antonio Sáenz y Pedro Somellera, y por los temas trabajados por los tesistas, le permite argumentar a Candioti que la institución se convirtió "en un centro de difusión de nuevas doctrinas y de críticas, no siempre leves, hacia el orden jurídico y la organización judicial vigente". De allí saldrían -al igual que ocurría con la Academia de Jurisprudencia- propuestas y proyectos elaborados por expertos que impactaban en la opinión pública local e incidían en la agenda de los gobiernos.

La tercera parte del libro, denominada "La revolución en los tribunales. Jueces, litigantes y formas de hacer justicia en el foro porteño", se sumerge de lleno en el perfil social y las prácticas de los actores. Si en la primera parte del libro predomina el análisis político e institucional, y en la segunda una indagación en torno a las ideas y los discursos, la tercera parte se inicia con un capítulo de historia social. Así, la autora demuestra su destreza en el manejo de distintos enfoques historiográficos. En general, la historiografía había abordado la injerencia de los gobiernos revolucionarios en la esfera de la justicia, resaltando la temprana remoción de casi todas las autoridades judiciales provenientes de la época tardocolonial. Sin embargo, poco se sabía del perfil social y profesional de los nuevos jueces surgidos del proceso revolucionario. En el capítulo 5 se elabora una biografía colectiva de los jueces de primera instancia, visualizando tanto continuidades como rupturas, siendo éstas últimas mucho más visibles a partir de 1820. La autora además repasa el modo de elección de los jueces, muestra como se parte de una elección cerrada al interior de la elite capitular para luego experimentar un efímero intento de elección popular y finalmente se opta por un "esquema centralizado de designación gubernamental".

En el capítulo 6, los expedientes judiciales hacen su entrada en escena en el relato, pero de forma muy distinta a como suelen ser utilizados por los historiadores. Practicando una historia plenamente judicial y/o procesal, se analiza en forma minuciosa el funcionamiento cotidiano de la justicia real. Lejos de querer mostrar si predomina en forma tajante la continuidad o la ruptura, Candioti afirma que los actores hacían un uso coyuntural y estratégico de argumentos pertenecientes a lógicas a veces contrapuestas. Por ejemplo, las condenas explícitas al arbitrio judicial convivían con apelaciones a ciertos valores como la piedad o equidad que debían practicar los jueces. Y las críticas al derecho colonial podían convivir sin problema con la cita de corpus legislativos como Las Siete Partidas de Alfonso el Sabio o la Recopilación de Leyes de Indias. La autora también destaca ciertos cambios en el marco del proceso, tales como 
la presencia del padrino al momento de la confesión, la invocación del decreto de seguridad individual de 1811, o el uso de nuevos argumentos como la libertad, la seguridad o el patriotismo. Este capítulo final concluye con una frase que sintetiza la evidencia aportada: ni "transformación definitiva y unilateral de la justicia y la ley", ni "insignificancia de los cambios retóricos y prácticos introducidos por la revolución".

El libro se cierra con un "Epílogo" donde se resumen las principales hipótesis de cada capítulo. Allí también la autora sitúa su aporte en el contexto historiográfico general. De esta forma, Un maldito Derecho...se enmarca en la nueva historia política que desde las obras pioneras de François-Xavier Guerra ha renovado nuestra mirada sobre el proceso independentista hispanoamericano. La obra de Candioti metodológicamente es tributaria de esta tradición, pero al mismo tiempo la trasciende, dado que una característica de ésta fue su escaso interés por las transformaciones acontecidas en los aspectos jurídicos. En momentos en que la mayoría de los estudios relacionados a la ley conocen dos modos de aproximación -la historia crítica del derecho y la historia social de la justicia-, la historia política de la justicia que propone la obra se presenta como un enfoque innovador y fecundo.

A partir de la publicación de Un maldito Derecho...podemos decir sin temor a equivocarnos que el vendaval de guerra, revolución y trastorno de todos los órdenes de la vida social acontecido entre 1806 y 1830 afectó también profundamente a la justicia, al menos en Buenos Aires. Creemos que el libro no solo es un excelente estudio de caso, además aporta preguntas y herramientas analíticas muy útiles para dar cuenta de problemáticas similares para el mismo período en otras regiones. Seguramente alguien podría argumentar, con cierta dosis de razón, que la experiencia porteña es más bien la excepción y no la regla en el ámbito rioplatense. La radicalidad de la "feliz experiencia" en Buenos Aires a partir de 1820 es difícil de encontrar en otras latitudes. Sin embargo, no es menos cierto que a lo largo de esa década los Estados provinciales se construyeron y consolidaron como entidades políticas independientes, con regímenes de gobiernos republicanos, representativos y dotados de cartas constitucionales en la mayoría de los casos. Este fenómeno, escasamente estudiado por la historiografía, recién en las últimas décadas está siendo indagado por autores provenientes de la historia política y la historia crítica del derecho. La intersección y el diálogo entre estas dos corrientes historiográficas es una buena noticia entre los historiadores, y la publicación de este libro es una prueba cabal de ello. Esperamos que este camino siga profundizándose y dando buenos frutos en el futuro inmediato. 